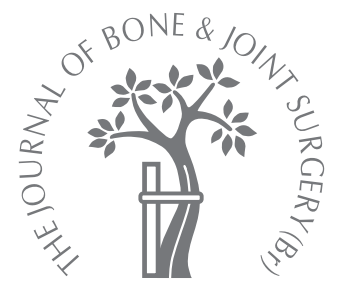

- REVIEW ARTICLE

\title{
Repair in the central nervous system
}

J. FitzGerald,
J. Fawcett

From Cambridge

University Centre for

Brain Repair,

Cambridge, England

The subject of central nervous system damage includes a wide variety of problems, from the slow selective 'picking off' of characteristic sub-populations of neurons typical of neurodegenerative diseases, to the wholesale destruction of areas of brain and spinal cord seen in traumatic injury and stroke. Experimental repair strategies are diverse and the type of pathology dictates which approach will be appropriate. Damage may be to grey matter (loss of neurons), white matter (cutting of axons, leaving neurons otherwise intact, at least initially) or both. This review will consider four possible forms of treatment for repair of the human central nervous system.

Repair of grey matter is the goal in degenerative neurological conditions where, despite the loss of characteristic cell populations such as the dopaminergic cells of the substantia nigra in Parkinson's disease, the general architecture of the surrounding tissue is left intact. Repair strategies include the transplantation of embryonic neurons or neural stem cells into affected areas of the brain in the hope that they will survive, integrate, and form functionally-appropriate connections. Trauma is a far more destructive process than neurodegeneration: damaged areas of grey matter are effectively completely destroyed, and repair would involve feats of tissue engineering way beyond what current science is capable of. Realistically, therefore, treatment of traumatic central nervous system (CNS) injury is limited to repair of white matter, i.e., the promotion of axon regeneration. Attention has focused mainly on the spinal cord, for two reasons. First, many spinal cord injuries are essentially purely white matter problems; although a thoracic cord transection affects segmental grey matter as well as longitudinal white matter tracts, the loss of activity in a few intercostal muscles due to the former is of negligible importance compared with the paraplegia due to the latter. In contrast, head injury is almost always a combined grey/white problem. Second, there are good, reproducible animal models of spinal cord injury, including contusion and transection, which produce motor and sensory deficits that are measurable both behaviourally and electrophysiologically, and are analogous to those seen in human spinal cord injury. Head injury in humans usually affects areas such as the frontal or temporal lobes and/or produces widespread diffuse injury, the main neurological deficits in survivors being in 'higher' functions such as memory and personality, which are difficult to model adequately in animals. Such lesions would also be much harder to generate experimentally in a reproducible way.

Besides white matter repair, there is a second important treatment strategy: the induction of neural plasticity. Plasticity is the ability of the CNS to 'rewire' itself by forming new neuronal connections. If this process could be promoted and optimised, a considerable improvement in disability might be brought about by making the best use of surviving (and regenerated) tissue. Stroke is another pathology that results in substantial or complete destruction of geographical regions of the brain, which at present cannot be directly repaired. This condition too could potentially benefit from treatments that induce plasticity and persuade perilesional brain areas to take over lost functions.

At present there are no treatments with clinically established efficacy that actively promote repair of the human CNS. Medical treatment focuses initially on stabilisation and prevention of further damage (thus, for example, unstable spines are fixed orthopaedically, and expanding intracranial or spinal blood clots are evacuated), and subsequently on rehabilitation and the provision of prosthetics and mechanical aids. However, basic science has made huge strides in recent years, and new treatments that promote axon regeneration, remyelination and plasticity will enter clinical practice, bringing significant 
changes in patient treatment. Some of these are approaching or are already in the early phases of clinical trials.

\section{Pathology of injury to the central nervous system}

Traumatic damage to the CNS occurs in two stages. The primary injury is the mechanical damage that occurs at the time of trauma. This is because of direct impact to CNS tissue, shock waves travelling through the tissue, or shearing forces generated by deceleration (the latter typically affecting the subcortical boundary between grey and white matter). Penetrating injuries producing laceration of CNS tissue are uncommon in the United Kingdom: most brain injuries are blunt, and result from the brain being shaken and impacting on the interior of an unbroken skull, and the most common spinal cord injury is contusion due to mechanisms such as fracture/dislocation rather than complete physical transection. Axons in the injured region may be severed and cells of all types mechanically destroyed. Damage to the microvasculature may lead to areas of ischaemic necrosis.

Secondary injury describes a variety of phenomena that follow over a period ranging from hours to weeks. Most seriously, injured CNS tissue is prone to oedema, and the consequent elevated intracranial pressure is a common and frequently fatal complication in the hours or days that follow a major head injury. Control of intracranial pressure by medical means (typically ventilation, head-up positioning to reduce impediment to venous return, and the use of osmotic diuretics), coupled with the use of inotropes to maintain cerebral perfusion pressure, is the mainstay of acute head injury management. Wide decompressive craniectomy in the event of failure of these simple measures is controversial, and evidence of improved long-term outcome has not yet been demonstrated, possibly because it prevents the immediate death of those patients with the most severe brain injuries. The procedure is the subject of an ongoing clinical trial. ${ }^{1}$

Disintegration of the blood brain barrier after injury leads to ingress of macrophages from the bloodstream. Microglia from the surrounding tissue converge on the injury site. Perilesional astrocytes alter their phenotype and over several weeks form a 'glial scar' composed of astrocytes and a dense extracellular matrix. ${ }^{2}$ Oligodendrocyte precursor cells, present throughout the mature CNS, proliferate $^{3}$ in the surrounding tissue and synthesise several inhibitory substances. ${ }^{4}$ If the surface of the CNS is breached, meningeal cells enter and, together with astrocytes, form a further barrier on the damaged surface. ${ }^{5}$ The glial scar serves to wall off damaged areas, limiting the area affected by secondary damage, but unfortunately the extracellular matrix is rich in several molecules that are inhibitory to regeneration. Apoptosis, necrosis of devascularised tissue and persistent inflammation may lead to progressive cystic cavitation, a further barrier to axonal regrowth.

Stroke generally causes a more precisely defined geographical area of destruction. Life-threatening swelling is uncommon, but secondary injury may occur in the 'ischaemic penumbra' at the watershed with adjacent vascular territories.

\section{Axon regeneration}

Why axons in the central nervous system do not regenerate. It was observed long ago that severed axons in the CNS do not have the ability to regrow any significant distance, ${ }^{6}$ and the prevailing belief was that they were essentially incapable of doing so. In 1980, it was shown that lengths of peripheral nerve implanted in spinal cord lesions could support the regeneration of CNS axons over several centimetres, ${ }^{7,8}$ but also that the axons would not grow out of the far end of the graft back into the CNS. Thus the failure of axons in the CNS to regenerate is largely due to the non-permissive nature of the environment they inhabit. If these inhibitory cues can be identified and removed, or if suitable growth-promoting agents can be added, then axons might be persuaded to regrow through the injury site. Several growth inhibitors have been identified which are either components of the extracellular matrix present in the glial scar ${ }^{2}$ or molecules associated with CNS myelin. 9

Inhibition by components of the glial scar. Key classes of inhibitory molecules are 1) chondroitin sulphate proteoglycans; 2) ephrins; and 3) semaphorins, all of which are upregulated following injury. Chondroitin sulphate proteoglycans are components of the CNS extracellular matrix; the precise mechanism by which they cause growth inhibition is not known, but the fact that they do so is well established. ${ }^{10,11}$ Ephrins and their Eph receptors are a family of membrane proteins that are involved in axon guidance during development, but are also present in the CNS in adulthood. Binding of ephrins on one cell to their receptors on another activates bidirectional signalling pathways that in neurons lead to the collapse of the growth cone. ${ }^{12}$ Upregulation of Eph-B3 receptors has been demonstrated in both astrocytes and neurons following spinal cord injury in the rat. ${ }^{13}$ Semaphorins are a large family of membrane-bound and secreted proteins that are also involved in axon guidance during development. Upregulated production of Sema$3 \mathrm{~A}$ by the meningeal cells that migrate in to form the lesion core ${ }^{14}$ is again inhibitory to axonal growth.

Inhibition by myelin-associated molecules. Cultured neurons grow readily on substrates of myelin extracted from peripheral nerve, but not on beds of mature oligodendrocytes or isolated CNS myelin. ${ }^{15}$ In animals where myelination is prevented by neonatal irradiation there is a degree of spontaneous regeneration of lesioned corticospinal tract axons. ${ }^{16}$ The proteins Nogo- $\mathrm{A}^{17,18}$ and myelin-associated glycoprotein have been identified as mediators of the growth-suppressive effects of CNS myelin. In addition, oligodendrocytes secrete the inhibitory protein tenascin R.

\section{Treatments in or approaching clinical trials}

Four potential treatments have been successful in promoting axonal regeneration and behavioural recovery in a range of spinal cord injury and other damage models. Two of these, antibodies against Nogo-A and a Rho inhibitor, are currently in the early stages of trials for the treatment of 


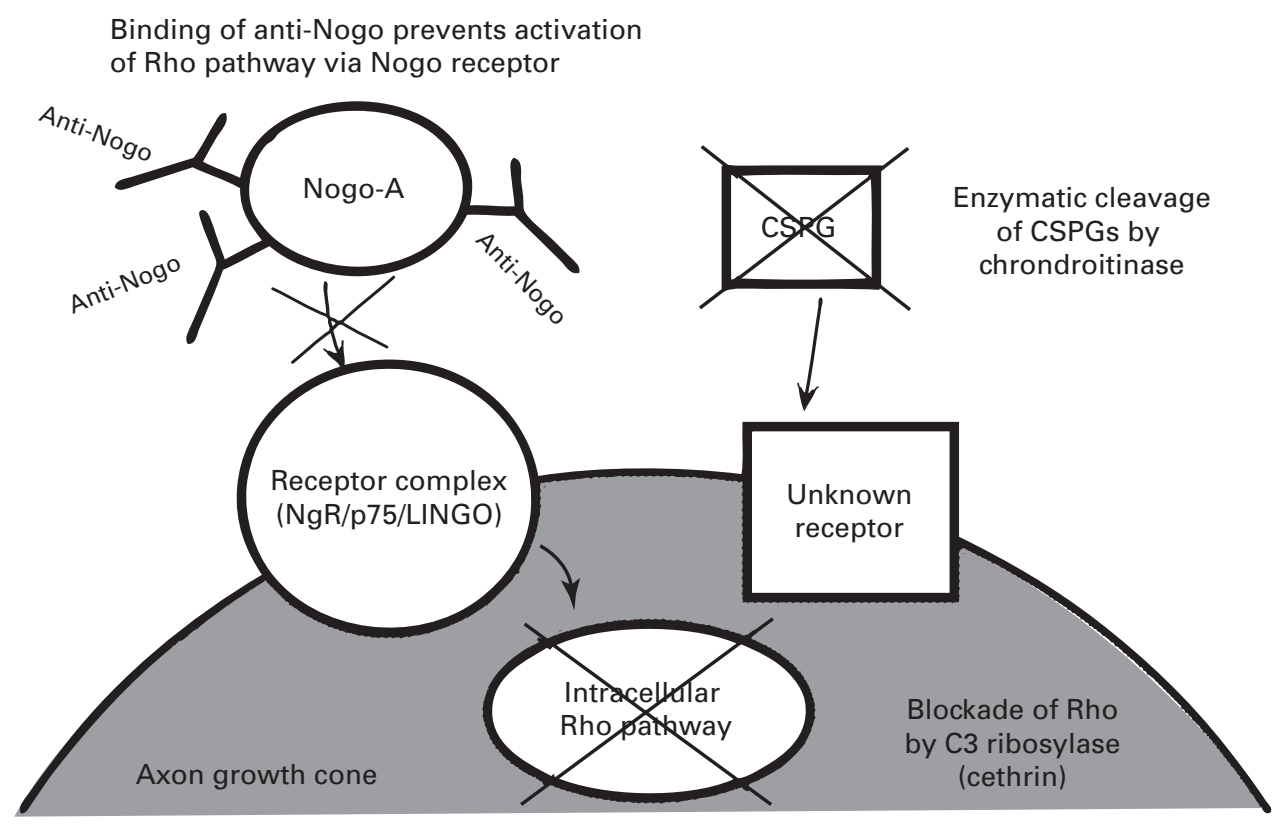

Fig. 1

Diagram showing mechanisms of treatment to promote axonal regeneration.

spinal cord injury. Chondroitinase and olfactory glial cell implants should reach trials soon (Fig. 1).

Anti-Nogo. Several monoclonal antibodies directed against Nogo-A neutralise the inhibitory properties of myelin both in vitro ${ }^{19}$ and in vivo, ${ }^{20,21}$ and have improved locomotor recovery after spinal cord injury in the rat. ${ }^{22,23}$ Progressing to a primate model, enhanced axon regeneration and neurological function have been demonstrated in the corticospinal tract of the monkey after thoracic spinal cord injury. ${ }^{24}$ A humanised version of the antibody (ATI355), infused into the injury site via a cannula, is undergoing phase I human trials under the aegis of the European Multicentre Study about Spinal Cord Injury. ${ }^{25}$

Rho inhibition. Many of the inhibitory signals described above (ephrins, Nogo) converge on the intracellular molecule Rho-A, which is a key mediator of actin depolymerisation and hence inhibition of axonal elongation. Blocking Rho-A might in theory negate a whole set of inhibitory influences. Enzymatic inactivation of Rho-A, or blockade of its downstream target Rho kinase, has been shown to promote axonal regeneration in the optic nerve of the adult rat $^{26}$ and regeneration of corticospinal tract axons after spinal cord injury in mice, with consequent improvement in locomotor function. ${ }^{27}$ The Rho inhibitor cethrin is administered as a gel to the injury site at acute decompression of the traumatised spinal cord. In phase I human trials in a cohort of 37 patients it has been reported to be safe and well tolerated. ${ }^{28}$ Trials are ongoing.

Chondroitinase. The enzyme chondroitinase cleaves chondroitin sulphate proteoglycans and reduces the growth-inhibiting properties of glial scar-derived astrocyte cultures in vitro. ${ }^{29}$ In rats, locally administered chondroitinase has been shown to improve locomotor and sensory recovery after cervical cord injury, ${ }^{30}$ to improve locomotion and bladder function after thoracic cord contusion, ${ }^{31}$ and to facilitate regeneration of axons in the brain after nigrostriatal tractotomy. ${ }^{32}$ Human trials are anticipated.

Olfactory ensheathing cells. The active element of the olfactory epithelium in the upper nasal cavity is the olfactory receptor neuron, whose apical surface carries receptors for specific airborne molecules. Axons from these cells are grouped into bundles that pass superiorly through perforations in the cribriform plate of the ethmoid bone to reach the anterior cranial fossa, where they enter the olfactory bulbs lying on the inferior surface of the frontal lobes. There they synapse with second-order neurons whose axons pass posteriorly in the olfactory tracts to enter the brain. Olfactory ensheathing cells are glial cells that have features of both astrocytes and peripheral Schwann cells. They wrap (but do not myelinate) the olfactory receptor cell axons all the way up and into the olfactory bulb. ${ }^{33}$ Uniquely among CNS glia, however, the olfactory ensheathing cells are conducive to axon growth in adulthood. Olfactory receptor neurons, like other epithelial cells, are continuously turned over, being replenished several times each year from a basal pool of olfactory stem cells. ${ }^{34}$ Olfactory ensheathing cells conduct the axons of new olfactory receptor cells towards and into the olfactory bulb to re-establish contact with the secondorder neurons. ${ }^{35}$ Strikingly, if the olfactory bulbs are removed the olfactory ensheathing cells are capable of conveying the axons into the frontal lobe instead, ${ }^{36}$ although it 
should be noted that this was observed in the neonatal mouse, where myelin is both less abundant and immature.

Might, then, transplants of such cells be capable of conducting regenerating spinal axons through the milieu of the lesion site itself and onward into more normal CNS tissue? In rat models of spinal cord injury, transplanted olfactory ensheathing cells encourage axonal growth, ${ }^{37,38}$ and this appears to translate into functional improvements in locomotion and climbing, ${ }^{39}$ although other authors have disputed their growth-promoting effects. ${ }^{40}$ Early human studies in spinal cord injury have involved the implantation of various forms of graft, ${ }^{41-43}$ including suspensions of cultured autologous olfactory ensheathing cells. Unfortunately, most of these studies have been without control groups or follow-up data, and have therefore given little convincing indication of the safety or efficacy of the treatment. There has been one small safety trial with a control group in Australia, ${ }^{44}$ which demonstrated no adverse effects in three patients with the American Spinal Injury Association (ASIA) grade A (complete) thoracic cord injury after follow-up of one-year post grafting. ${ }^{45}$

Echoing their normal function of guiding olfactory axons from the periphery into the CNS, there is also experimental evidence that olfactory ensheathing cells can conduct the regrowing proximal axons of dorsal root ganglion cells back into the spinal cord after dorsal root transection and reimplantation. ${ }^{46}$ This has obvious potential for the treatment of brachial plexus root avulsion, and trials of olfactory ensheathing cells in this setting are expected to begin soon.

\section{Other experimental treatments}

Prevention of glial scar formation. The cytotoxic drug cytosine arabinoside has been used to eliminate proliferating cells after a lesion of the nigrostriatal tract. ${ }^{3}$ This removes oligodendrocyte precursor cells from the lesion site and has a short-lived effect on the astrocytic response, but unfortunately produces only a transient increase in axonal regeneration, with the axons subsequently retracting. Ethidium bromide ablates all glial cells, and when administered in a similar model produces a more robust increase in numbers of regrowing axons. ${ }^{47}$

Administration of growth factors. Neurotrophin-3 (NT3) has been shown to promote the regeneration of ascending and descending fibres after spinal cord injury in the rat. ${ }^{48}$ The most successful strategy has been to graft an island of fibroblasts or bone marrow cells derived from the same animal and engineered to secrete NT3 into the spinal cord below a lesion. This attracts axons, including those from the corticospinal tract, and partly restores function. ${ }^{49,50}$ Grafts of bone marrow cells ${ }^{51}$ or fibroblasts ${ }^{52}$ modified to secrete brain-derived neurotrophic factor have also been shown to stimulate axonal growth in the dorsal columns and rubrospinal tract, ${ }^{51,52}$ respectively, in the rat, accompanied in the latter case by significant functional recovery.

Schwann cells. The growth-promoting properties of peripheral nerve grafts are largely due to the components of the extracellular matrix and neurotrophic factors secreted by Schwann cells. ${ }^{53}$ Grafting Schwann cells into CNS injury sites has therefore been explored as a possible means of promoting regeneration. Grafts implanted into rat spinal cord contusions immediately after injury have been shown to reduce astrogliosis and cavitation. ${ }^{54}$ Schwann cells loaded into polymeric guidance support the growth of axons from both proximal and distal stumps of the transected rat thoracic cord. ${ }^{55}$ Unfortunately, most axons come from neurons close to the injury, with relatively few supraspinal neurons sending their axons through the grafts. There is also a problem with Schwann cell grafts, known as the 'off-ramp' problem, which means that axons will enter and grow through the grafts but cannot cross back into CNS tissue at the other end. The addition of growth factors (brain-derived neurotrophic factor and NT3) to the graft can induce regeneration of some types of supraspinal axons through it, ${ }^{56}$ with a few being able to exit it, but probably not in clinically significant numbers.

\section{Growth beyond the lesion site}

We must first persuade axons to grow from the lesion site back into the CNS. The fact that olfactory ensheathing cells can conduct axons from the peripheral system to the CNS suggests that they might be the basis of one possible solution to this problem. ${ }^{36}$ Once across this boundary, however, axons must elongate over considerable distances in the CNS tissue beyond in order to reach their target. Encouragingly, there is some evidence that the uninjured CNS may not be as inhibitory as previously thought. This is technically difficult to demonstrate because it is hard to perform experiments to test how well axons grow in the CNS without damaging it and creating a glial scar. This confounding element was removed in a rat model where suspensions of dorsal root ganglion neurons were injected into cerebral white matter in extremely small volumes so as to avoid tissue damage. ${ }^{57}$ Neurons in those transplants that were judged atraumatic (as evidenced by low levels of reactive extracellular matrix molecules) were seen to extend axons for considerable distances along white matter tracts. It appears that the inhibitory myelin-associated molecules may only exert their influence when the myelin has been damaged.

Having deployed various treatments to make the injury site and surrounding area as permissive as possible, and possibly implanted cells or injected molecular cues a short distance away in order to entice axons through the lesion boundary into the 'normal' CNS tissue, we are now asking the axon to grow away from these attractants. During development, axon guidance cues are progressively regulated so that attractants are always expressed ahead of the growing axon and removed from behind it. Such regulation may not be possible in, for example, growth factor-secreting fibroblast transplants. It has been suggested that multiple grafts may be required at intervals along the regenerating tract as a series of 'relay islands' to provide chemoattraction from ahead.

Finally, it may not be necessary for axons to grow all the way back to their original target in order to provide useful 
reinnervation. An axon that regrows a relatively modest distance may be able to establish a connection with, for example, a neuron in the premotoneuronal network of the cervical $\operatorname{cord}^{58}$ that will relay its signals into an uninjured axon nearby. Plastic changes will allow the brain to adapt to this rerouting.

\section{Plasticity}

Regeneration of lost axons or tissue is not the sole mechanism by which recovery of function after CNS injury might be achieved. The majority of spinal cord transections are incomplete, ${ }^{59}$ and disability could potentially be reduced by allowing those neurons with surviving axons to be 'rewired' to make best use of the residual connectivity with the distal cord. Likewise, disability due to loss of cerebral grey matter as a result of head injury or stroke might be ameliorated if surviving cortex could be persuaded to take over some of the functions previously subserved by damaged areas. Neuronal 'rewiring' is termed plasticity, and occurs through alterations in the potency of synapses between neurons and through the sprouting of side branches from axons to form entirely new synapses with other neurons.

Plasticity is a normal process in post-natal development, when sensory input is crucial in sculpting immature neuronal circuitry throughout the CNS to produce the eventual normally functioning pattern of connections seen in adulthood. A well-studied example is the visual system. An adult with the visual acuity of a newborn baby would be considered legally blind; rapid modification and refinement of retinal and cortical circuitry allows acuity to approach that of an adult after approximately six months, but the process is not complete for several years. Development is absolutely dependent on the presence of normal sensory input, and abnormal input during this period can permanently prevent the acquisition of normal vision. In the visual cortex individual neurons are grouped into small alternating zones of 'ocular dominance' that preferentially respond to input from one or other eye. Classic experiments in kittens ${ }^{60}$ demonstrated that if sensory input is abnormal, these areas of ocular dominance fail to develop properly. Animals with one eye sutured shut after birth ('monocular deprivation') do not develop areas primarily responsive to that eye, devoting the entire cortex to the open eye. Opening the eye allows dominance areas for that eye to develop, but only when it is opened before the animal reaches a characteristic age. The time up until this age is called the critical period, because of this vulnerability of development to abnormal input. After the end of the critical period, even if the eye is opened the corresponding ocular dominance areas never develop properly and the vision in the eye is never normal. Conversely, monocular deprivation starting after the critical period has closed does not abolish the cortical representation of the deprived eye: adult cataract patients promptly recover normal vision in the eye when the lens is replaced, even if the eye has been blind for many years. This is all because the critical period is a time of great plasticity. At the closure of the critical period plasticity is dramatically reduced, cementing in place the now fully developed neural circuitry. The critical period in humans appears to close at about the age of six years.

Some plasticity does occur physiologically in adulthood, although to a much lesser degree than during the critical period in infancy. Adult monkeys with an amputated finger initially have a corresponding 'silent' area of primary sensory cortex, but in time re-organise their cortical maps to apportion the vacated part of the sensory homunculcus to adjacent digits. ${ }^{61}$ Monkeys trained in a task that involves intensive sensory input from one or two digits expand the cortical representation of the areas concerned at the expense of neighbouring regions, ${ }^{62}$ so as to allow a finer spatial resolution in these highly active sites. Studies on adult humans using magnetoencephalography show similar effects of training on the distribution of cortical maps; thus Braille readers have expanded cortical areas representing their reading finger, ${ }^{63}$ and violinists have enlarged representations of the fingers of the left hand. ${ }^{64}$ The adult brain, however, does not have sufficient plasticity to cope so well with significant tissue damage. The effect of stroke on the motor areas of the brain has been studied using functional MRI and positron emission tomography (PET). ${ }^{65}$ Initially there are widespread changes in motor cortical activity, but gradually the ectopic activity becomes focused in perilesional areas as they adapt plastically to take over the function of the damaged region, and it appears that the better such localisation, the better the functional recovery. The ability of the brain to do this will depend on its age and premorbid state, and the extent of the damage.

Just as with failure of axonal regeneration, the relatively low level of adult neural plasticity is now known to be largely a result of inhibitory extracellular factors rather than an intrinsic property of CNS neurons. Closure of the critical period coincides temporally with the synthesis and deposition of extracellular matrix components, ${ }^{66}$ including chondroitin sulphate proteoglycans that envelop neuronal cell bodies in a structure known because of its reticular microscopic appearance as the 'perineuronal net', ${ }^{67}$ which prevents the formation of new synapses. Cleavage of the chondroitin sulphate proteoglycans with chondroitinase has been shown to reactivate ocular dominance plasticity in the adult rat visual cortex. ${ }^{68}$ After experimental spinal cord injury in the rat, chondroitinase treatment causes extensive sprouting of axons when delivered to the brainstem ${ }^{69}$ or spinal cord, ${ }^{70}$ and leads to functional improvement.

Nogo-A also has a prominent role in the limitation of plasticity. Inhibition with the monoclonal antibody IN-1 in a rat model of stroke causes an increase in dendritic arborisation and spine density, ${ }^{71}$ which is associated with improved functional recovery. After a focal adult rat sensorimotor cortex lesion, IN-1 permits the reinnervation of denervated subcortical areas by axons from the intact contralateral hemisphere, ${ }^{72}$ which also improves functional outcome. ${ }^{73}$

Inosine is a purine nucleoside which has been shown to promote axonal sprouting in adult CNS neurons by activating an intracellular signalling pathway which regulates several genes involved in axonal growth. ${ }^{74}$ Unlike chon- 


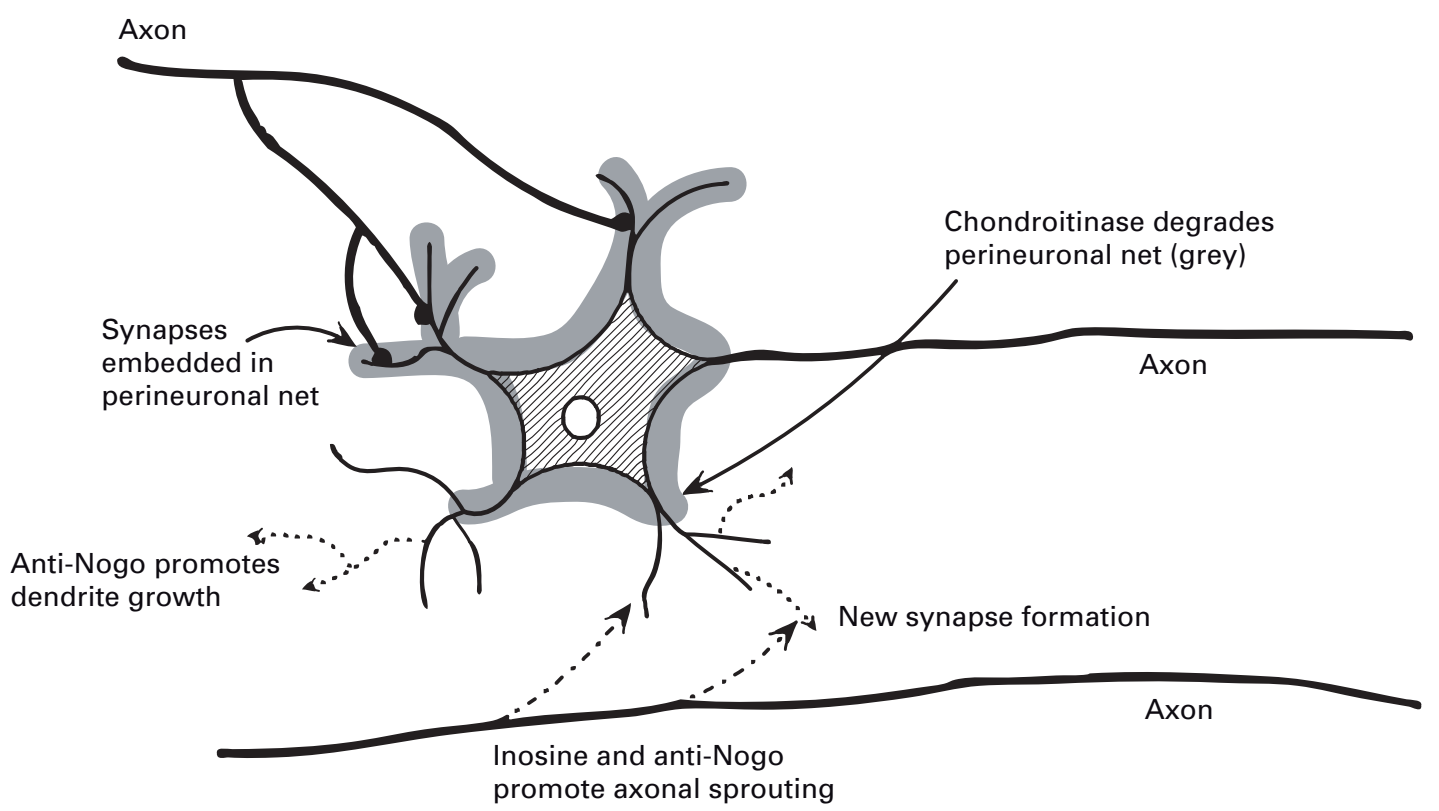

Fig. 2

Diagram showing mechanisms of treatment to promote plasticity.

droitinase, which needs to be injected at the target site, inosine is a small molecule that diffuses widely throughout the cerebrospinal fluid and into CNS tissue. When given by continuous infusion into the cerebrospinal fluid in rats it has been shown to improve outcome after experimentallyinduced middle cerebral artery territory stroke. ${ }^{75}$ Recently we have demonstrated therapeutic benefit from intraventricular infusion of inosine in a rat model of traumatic brain injury. ${ }^{76}$ Brain-derived neurotrophic factor administered in the vicinity of the cell bodies of injured corticospinal neurons promoted axonal sprouting, and these sprouts connected with spared descending interneurons. ${ }^{77}$ These effects were correlated with functional improvement, albeit not significantly so.

Regenerating axons have a tendency to misroute and reinnervate the wrong target. In peripheral nerves, regenerating axons regrow down the columns of Schwann cells left behind when the axon distal to the injury degenerates ${ }^{78}$ after losing its connection to the cell body. If the injury is a crush or stretch, so that the axons are damaged but the connective tissue structure of the nerve is preserved (axonotmesis), then these Schwann cell columns should guide each axon back to its original target. However, if the nerve is severed (neurotmesis) and has to be stitched together, it is highly unlikely that many of the Schwann cell columns in the proximal and distal stumps will be correctly paired up, so this guidance system is lost and axons frequently take the wrong path. ${ }^{79}$ Motor axons growing to sensory targets and vice versa are functionally useless, and even if the fibre type is correct the regenerating axon may grow down a track leading to a completely different muscle or area of skin from the original fibre it replaces, with function- ally poor results. This is more of a problem with proximal injuries, where fascicles contain mixed-fibre types and are highly plexiform, ${ }^{80}$ and is one of the factors to blame for the generally poor results of proximal nerve and brachial plexus repair. ${ }^{81}$ It has recently been shown that cervical cord treatment with chondroitinase enhanced functional recovery after median and ulnar nerve repair in the adult rat. ${ }^{82}$ There is no obvious reason why regenerating axons in the CNS should be immune from such misrouting problems. Thus even if a majority of CNS axons can be persuaded to regenerate and establish distal connections with grey matter, these connections are likely to be at best approximately correct, and we will therefore probably need plasticity treatments as well as regenerative treatments in order to re-organise the new connections. It is fortuitous that some of the treatments that promote axon regeneration are also key players in the induction of plasticity (Fig. 2). Chondroitin sulphate proteoglycans and Nogo-A inhibit both the long-range regrowth of axons and the shortrange sprouting of collaterals that underlies plasticity. Administration of chondroitinase and anti-Nogo antibodies will, in general, facilitate both processes.

\section{How good a repair do we need?}

During removal of slow-growing extramedullary spinal tumours such as meningiomas, in humans it is sometimes observed that the cord has been gradually compressed over a long period into little more than a ribbon, yet the patient has frequently only recently developed neurological symptoms. This suggests that, as with many other body systems, there is a substantial degree of functional reserve and quite large amounts of damage may be tolerated without major deficit. 
The corollary is that it should be possible to produce a good functional recovery by restoring only a relatively small part of the original neuronal circuitry. Improved forepaw function following corticospinal tract division in the rat and olfactory ensheathing cells transplantation has been associated with regeneration of just $1 \%$ of corticospinal tract axons. ${ }^{83}$ Plasticity may well have a role to play in optimising recovery if regeneration-promoting treatments are successful in restoring a small number of axonal connections across the divide.

\section{The difficulties of extrapolation from rat to humans}

Only about one-third of promising results from animal models successfully translate into therapeutic successes in human trials, ${ }^{84}$ and where there is success the process takes a median of seven years. In the CNS, the most obvious difference between the rat (the most common model) and the human is in scale. The human spinal cord is ten times as long as that of the rat, yet the neurons which are expected to regenerate their axons are biologically very similar, so a much greater feat of restoration is required of the human nerve cell. Not only that, but axons regrow slowly. Regenerating peripheral axons in humans manage about a millimetre per day, and it is doubtful that central ones, even if freed from all their normal inhibitions, would move any faster, as even under favourable conditions their regenerative efforts are intrinsically less robust than those of peripheral neurons. ${ }^{85}$ We will therefore have to wait much longer than in the animal model to judge whether our regenerative treatments have been a success. Plasticity-based treatments may be less affected by issues of physical and temporal scale, being dependent on synaptic modulation, which requires no growth, and on axonal sprouting to form new connections, which requires relatively short-range growth. Plasticity treatments have another attraction, which is that they will probably be effective for a considerable period after the damage has occurred, whereas axon regeneration treatments are mainly effective just after injury.

\section{Conclusion}

Repair of the human CNS has until recently appeared impossible, but we now have four potential treatments that are either in or approaching early clinical trials. Early trials of the Rho inhibitor cethrin are encouraging, and anti-Nogo is also in a phase I study. Trials of chondroitinase and olfactory ensheathing cells are expected in the near future. Looking to the future, the regeneration of severed axons by cellular and molecular treatments and the induction of plasticity to rewire, and thus make optimal use of, surviving and regenerated CNS tissue are goals that are looking ever more achievable.

\section{References}

1. Hutchinson PJ, Corteen E, Czosnyka M, et al. Decompressive craniectomy in traumatic brain injury: the randomized multicenter RESCUEicp study (www.RESCUEicp.com). Acta Neurochir Supp/ 2006;96:17-20.

2. Fawcett JW, Asher RA. The glial scar and central nervous system repair. Brain Res Bull 1999;49:377-91.

3. Rhodes KE, Moon LD, Fawcett JW. Inhibiting cell proliferation during formation of the glial scar: effects on axon regeneration in the CNS. Neuroscience 2003:120:41 56 .
4. Levine JM, Reynolds R, Fawcett JW. The oligodendrocyte precursor cell in health and disease. Trends Neurosci 2001;24:39-47.

5. Mathewson AJ, Berry M. Observations on the astrocyte response to a cerebral stab wound in adult rats. Brain Res 1985;327:61-9.

6. Ramon y Cajal S. Degeneration \& regeneration of the nervous system. London: Oxford University Press, 1928

7. Richardson PM, McGuinness UM, Aguayo AJ. Axons from CNS neurons regenerate into PNS grafts. Nature 1980;284:264-5.

8. David S, Aguayo AJ. Axonal elongation into peripheral nervous system "bridges" after central nervous system injury in adult rats. Science 1981;214:931-3.

9. Filbin MT. Myeline-associated inhibitors of axonal regeneration in the adult mammalian CNS. Nat Rev Neurosci 2003;4:703-13.

10. McKeon RJ, Höke A, Silver J. Injury-induced proteoglycans inhibit the potential for laminin-mediated axon growth on astrocytic scars. Exp Neuro/ 1995;136:32-43.

11. Snow DM, Lemmon V, Carrino DA, Caplan AI, Silver J. Sulfated proteoglycans in astroglial barriers inhibit neurite outgrowth in vitro. Exp Neurol 1990;109:111-30.

12. Holland SJ, Gale NW, Mbamalu G, et al. Bidirectional signalling through the EPHfamily receptor Nuk and its transmembrane ligands. Nature 1996;383:722-5.

13. Miranda JD, White LA, Marcillo AE. Induction of Eph B3 after spinal cord injury. Exp Neurol 1999;156:218-22.

14. De Winter F, Oudega $\mathbf{M}$, Lankhorst AJ, et al. Injury-induced class 3 semaphorin expression in the rat spinal cord. Exp Neurol 2002;175:61-75.

15. Schwab ME, Caroni P. Oligodendrocytes and CNS myelin are nonpermissive substrates for neurite growth and fibroblast spreading in vitro. J Neurosci 1988;8:238193.

16. Savio T, Schwab ME. Lesioned corticospinal tract axons regenerate in myelin-free rat spinal cord. Proc Natl Acad Sci USA 1990;87:4130-3

17. Spillman A, Bandtlow CE, Lottspeich F, Keller F, Schwab ME. Identification and characterization of a bovine neurite growth inhibitor (bNI-220). J Biol Chem 1998:273:19283-93

18. Chen MS, Huber AB, van der Haar ME, et al. Nogo-A is a myelin-associated neurite outgrowth inhibitor and an antigen for monoclonal antibody IN-1. Nature 2000; $403: 434-9$

19. Caroni P, Schwab ME. Antibody against myelin-associated inhibitor of neurite growth neutralizes nonpermissive substrate properties of CNS white matter. Neuron 1988;1:85-96.

20. Schnell L, Schwab ME. Axonal regeneration in the rat spinal cord produced by an antibody against myelin-associated neurite growth inhibitors. Nature 1990;343:26972.

21. Brösamle C, Huber AB, Fiedler M, Skerra A, Schwab ME. Regeneration of lesioned corticospinal tract fibers in the adult rat induced by a recombinant, humanized IN-1 antibody fragment. J Neurosci 2000;20:8061-8.

22. Merkler D, Metz GA, Raineteau 0, et al. Locomotor recovery in spinal cord-injured rats treated with an antibody neutralizing the myelin-associated neurite growth inhibitor Nogo-A. J Neurosci 2001;21:3665-73

23. Bregman BS, Kunkel-Bagden E, Schnell L, et al. Recovery from spinal cord injury mediated by antibodies to neurite growth inhibitors. Nature 1995;378:498-501

24. Fouad K, Klusman I, Schwab ME. Regenerating corticospinal fibers in the Marmoset (Callitrix jacchus) after spinal cord lesion and treatment with the anti-Nogo-A antibody IN-1. Eur J Neurosci 2004;20:2479-82.

25. No authors listed. European Multicentre Study about Spinal Cord Injury. http:// www.emsci.org (date last accessed 17 October 2007).

26. Lehmann M, Fournier A, Selles-Navarro I, et al. Inactivation of Rho signaling pathway promotes CNS axon regeneration. J Neurosci 1999;19:7537-47.

27. Dergham P, Ellezam B, Essagian C, et al. Rho signaling pathway targeted to promote spinal cord repair. J Neurosci 2002;22:6570-7.

28. Fehlings MG, Theodore N, Harrop J, et al. Results of the Cethrin Phase I/Ila prospective clinical trial of a Rho inhibitor for the treatment of acute spinal cord injury. Procs 75th Annual Meeting American Association of Neurological Surgeons. 2007

29. McKeon RJ, Schreiber RC, Rudge JS, Silver J. Reduction of neurite outgrowth in a model of glial scarring following CNS injury is correlated with the expression of inhibitory molecules on reactive astrocytes. J Neurosci 1991;11:3398-411.

30. Bradbury EJ, Moon LD, Popat RJ, et al. Chondroitinase ABC promotes functional recovery after spinal cord injury. Nature 2002;416:636-40.

31. Caggiano AO, Zimber MP, Ganguly A, Blight AR, Gruskin EA. Chondroitinase $\mathrm{ABCl}$ improves locomotion and bladder function following contusion injury of the rat spinal cord. J Neurotrauma 2005:22:226-39.

32. Moon LD, Asher RA, Rhodes KE, Fawcett JW. Regeneration of CNS axons back to their target following treatment of adult rat brain with chondroitinase ABC. Nat Neurosci 2001:4:465-6.

33. Fiel P, Li Y, Raisman G. Ensheathment of the olfactory nerves in the adult rat. J Neurocytol 2003;32:317-24. 
34. Schwob JE. Neural regeneration and the peripheral olfactory system. Anat Rec 2002;269:33-49.

35. Doucette JR, Kiernan JA, Flumerfelt BA. The re-innervation of olfactory glomeruli following transection of primary olfactory axons in the central or peripheral nervous system. J Anat 1983;137(Pt 1):1-19.

36. Graziadei PP, Levine RR, Monti Graziadei GA. Plasticity of connections of the olfactory sensory neuron: regeneration into the forebrain following bulbectomy in the neonatal mouse. Neuroscience 1979;4:713-27.

37. Li Y, Field PM, Raisman G. Repair of adult rat corticospinal tract by transplants of olfactory ensheathing cells. Science 1997;277:2000-2.

38. Ramón-Cueto A, Plant GW, Avila J, Bunge MB. Long-distance axonal regeneration in the transected adult rat spinal cord is promoted by olfactory ensheathing glia transplants. J Neurosci 1998;18:3803-15.

39. Li Y, Decherchi P, Raisman G. Transplantation of olfactory ensheathing cells into spinal cord lesions restores breathing and climbing. J Neurosci 2003;23:727-31.

40. Lu P, Yang H, Culbertson M. Olfactory ensheathing cells do not exhibit unique migratory or axonal growth-promoting properties after spinal cord injury. J Neurosci 2006;26:11120-30

41. Senior K. Olfactory ensheathing cells to be used in spinal cord repair trial. Lancet neurol 2002;1:269.

42. Huang $\mathbf{H}$, Chen $\mathbf{L}$, Wong $\mathbf{H}$ et al. Influence of patients' age on functional recovery after transplantation of olfactory ensheathing cells into injured spinal cord injury. Chin Med J (Engl) 2003;116:1488-91.

43. Watts J. Controversy in China. Lancet 2005;365:109-10.

44. Féron F, Perry C, Cochrane J, et al. Autologous olfactory ensheathing cell transplantation in human spinal cord injury. Brain 2005;128:2951-60.

45. Marino RJ, Barres T, Biering-Sorenson F et al. International standards for neurological classification of spinal cord injury. J Spinal Cord Med 2003;26 (Suppl 1) :550-6.

46. Li Y, Carlstedt T, Berthold CH, Raisman G. Interaction of transplanted olfactoryensheathing cells and host astrocytic processes provids a bridge for axons to regenerate across the dorsal root entry zone. Exp Neuro/ 2004;188:300-8.

47. Moon LD, Brecknell JE, Franklin RJ, Dunnett SB, Fawcett JE. Robust regeneration of CNS axons through a track depleted of CNS glia. Exp Neuro/ 2000;161:49-66.

48. Bradbury EJ, Khemani S, Von R, et al. NT-3 promotes growth of lesioned adult rat sensory axons ascending in the dorsal columns of the spinal cord. Eur $\mathrm{J}$ Neurosci 1999;11:3873-83.

49. Tuszynski MH, Peterson DA, Ray J, et al. Fibroblasts genetically modified to produce nerve growth factor induce robust neuritic ingrowth after grafting to the spinal cord. Exp Neurol 1994;126:1-14.

50. Grill R, Murai K, Blesch A, Gage FH, Tuszynski MH. Cellular delivery of neurotrophin-3 promotes corticospinal axonal growth and partial functional recovery after spinal cord injury. J Neurosci 1997;17:5560-72.

51. Lu P, Jones LL, Tuszynski MH. BDNF-expressing marrow stromal cells support extensive axonal growth at site of spinal cord injury. Exp Neurol 2005;191:344-60.

52. Liu Y, Kim D, Himes BT, et al. Transplants of fibroblasts genetically modified to express BDNF promote regeneration of adult rat rubrospinal axons and recovery of forelimb function. J Neurosci 1999;19:4370-87.

53. Bixby JL, Lillien J, Reichardt LF. Identification of the major proteins that promote neuronal process outgrowth on Schwann cells in vitro. J Cell Biol 1988;107:353-61.

54. Martin D, Robe P, Franzen R, et al. Effects of Schwann cell transplantation in a contusion model of rat spinal cord injury. J Neurosci Res 1996;45:588-97.

55. Xu XM, Chen A, Guénard V, Kleitman N, Bunge MB. Bridging Schwann cell transplants promote axonal regeneration from both the rostral and caudal stumps of transected adult rat spinal cord. J Neurocyto/ 1997;26:1-16.

56. Xu XM, Guénard V, Kleitman N, Aebischer P, Bunge MB. A combination of BDNF and NT-3 promotes supraspinal axonal regeneration into Schwann cell grafts in adult rat thoracic spinal cord. Exp Neurol 1995;134:261-72.

57. Davies SJ, Fitch MT, Memberg SP, et al. Regeneration of adult axons in white matter tracts of the central nervous system. Nature 1997;390:680-3.

58. Lemon RN, Kirkwood PA, Maier MA, Nakajima K, Nathan P. Direct and indirect pathways for corticospinal control of upper limb motoneurons in the primate. Prog Brain Res 2004;143:263-79.

59. Kakulas BA. A review of the neuropathology of human spinal cord injury with emphasis on special features. J Spinal Cord Med 1999;22:119-24.

60. Wiesel TN, Hubel DH. Single-cell responses in striate cortex of kittens deprived of vision in one eye. J Neurophysiol 1963;26:1003-17.
61. Merzenich MM, Nelson RJ, Stryker MP, et al. Somatosensory cortical map changes following digit amputation in adult monkeys. J Comp Neurol 1984;224:591605 .

62. Jenkins WM, Merzenich MM, Ochs MT, Allard T, Guic-Robles E. Functiona reorganisation of primary somatosensory cortex in adult owl monkeys after behaviourally controlled tactile stimulation. J Neurophysiol 1990;63:82-104.

63. Pascual-Leone A, Torres F. Plasticity of the sensorimotor cortex representation of the reading finger in Braille readers. Brain 1993;116:39-52.

64. Elbert T, Pantev C, Wienbruch C, Rockstroh B, Taub E. Increased cortical representation of the fingers of the left hand in string players. Science 1995;270:305-7.

65. Ward NS. Plasticity and the functional reorganization of the human brain. Int J Psychophysio/ 2005;58:158-61.

66. Hockfield S, Kalb RG, Zaremba S, Fryer H. Expression of neural proteoglycans correlates with the acquisition of mature neuronal properties in the mammalian brain Cold Spring Harb Symp Quant Biol 1990;55:505-14.

67. Celio MR, Spreafico R, De Biasi S, Vitellarco-Zuccarello L. Perineuronal nets past and present. Trends Neurosci 1998;21:510-15.

68. Pizzorusso T, Medini P, Berardi N, et al. Reactivation of ocular dominance plas ticity in the adult visual cortex. Science 2002;298:1248-51.

69. Massey JM, Hubscher CH, Wagoner MR, et al. Chondroitinase ABC digestion of the perineuronal net promotes functional collateral sprouting in the cuneate nucleus after cervical spinal cord injury. J Neurosci 2006;26:4406-14.

70. Barritt AW, Davies M, Marchand F, et al. Chondroitinase ABC promotes sprouting of intact and injuried spinal systems after spinal cord injury. J Neurosci 2006;26:10856-67.

71. Papadopoulos CM, Tsai SY, Cheatwood JL, et al. Dendritic plasticity in the adult rat following middle cerebral artery occlusion and Nogo-a neutralization. Cereb Cortex 2006;16:529-36.

72. Kartje GL, Schulz MK, Lopez-Yunez A, Schnell L, Schwab ME. Corticostriata plasticity is restricted by myelin-associated neurite growth inhibitors in the adult rat. Ann Neurol 1999; 45:778-86.

73. Emerick AJ, Kartje GL. Behavioural recovery and anatomical plasticity in adult rats after cortical lesion and treatment with monoclonal antibody IN-1. Behav Brain Res 2004;152:315-25

74. Petrausch B, Tabibiazar R, Roser T, et al. A purine-sensitive pathway regulates multiple genes involved in axon regeneration in goldfish retinal ganglion cells. J Neurosci 2000;20:8031-41

75. Chen P, Goldberg DE, Kolb B, Lanser M, Benowitz LI. Inosine induces axonal rewiring and improves behavioral outcome after stroke. Procs Nat Acad Sci USA 2002;99:9031-6.

76. Smith JM, Lunga P, Story D, et al. Inosine promotes recovery of skilled motor function in a model of focal brain injury. Brain 2007;130:915-25.

77. Vavrek R, Girgis J, Tetzlaff W, Hiebert GW, Fouad K. BDNF promotes connections of corticospinal neurons onto spread descending interneurons in spinal cord injured rats. Brain 2006;129:1534-45.

78. Waller A. Experiments on the section of the glossopharyngeal and hypoglossal nerves of the frog, and observations of the alterations produced thereby in the structure of their primitive fibres. Philosophical Transactions of the Royal Society of London 1850;140:423-9.

79. Valero-Cabré A, Navarro X. Functional impact of axonal misdirection after peripheral nerve injuries followed by graft or tube repair. J Neurotrauma 2002;19:1475-85.

80. Sunderland $\mathbf{S}$. The intraneural topography of the radial, median and ulnar nerves Brain 1945;68:243-99

81. Kim D, Midha R, Murovic JA, Spinner R, Teil R. Kline and Hudson's nerve injuries Second ed. Philadelphia: Elsevier, 2007.

82. Galtrey CM, Asher RA, Nothias F, Fawcett JW. Promoting plasticity in the spinal cord with chondroitinase improves functional recovery after peripheral nerve repair. Brain 2007;130:926-39.

83. Keyvan-Fouladi N, Raisman G, Li Y. Functional repair of the corticospinal tract by delayed transplantation of olfactory ensheathing cells in adult rats. J Neurosci 2003;23:9428-34

84. Hackam DG, Redelmeier DA. Translation of research evidence from animals to humans. JAMA 2006;296:1731-2.

85. Fawcett JW. Intrinsic neuronal determinants of regeneration. Trends Neurosci 1992;15:5-8. 